\title{
Results of Parasitological Examinations of Faecal Samples from Cats and Dogs in Germany between 2003 and 2010
}

Dieter Barutzki $(\bowtie)$, Roland Schaper²

${ }^{1}$ Veterinary Laboratory Freiburg, Freiburg i. Br., Germany

2 Bayer Animal Health GmbH, Leverkusen, Germany

E-mail: barutzki@labor-freiburg.de

\begin{abstract}
In a retrospective study, the results of parasitological examinations of faecal samples from 8,560 cats and 24,677 dogs between January 2003 and December 2010 in Germany were analysed. $30.4 \%$ of the examined dogs and $22.8 \%$ of the cats were infected with endoparasites. The examination of the faecal samples from dogs revealed stages of Giardia spp. (18.6\%), Toxocara canis (6.1\%), Toxascaris leonina (0.6\%), Ancylostomatidae (2.2\%), Trichuris vulpis (1.2\%), Capillaria spp. (1.3\%), Crenosoma vulpis (0.4\%), Angiostrongylus vasorum (0.5\%), Taeniidae (0.4\%), Dipylidiidae (<0.1\%), Mesocestoides spp. (<0.1\%), Isospora spp. (5.6\%), I. ohioensis-complex (3.9\%), I. canis (2.4\%), Sarcocystis spp. (2.2\%) and Hammondia heydorni/Neospora caninum (0.3\%). Dogs in the age groups up to 3 months and $>3$ up to 6 months of age showed significantly higher infection rates with Giardia spp. (37.5\% and $38.2 \%$, respectively), Toxocara canis $(12.0 \%$ and $12.4 \%$,
\end{abstract}

respectively), Toxascaris leonina (1.1\% and $1.6 \%$, respectively), Isospora spp. (23.4\% and $11.8 \%$, respectively), I. ohioensis-complex (15.6\% and 7.2\%, respectively) and I. canis ( $11.8 \%$ and $5.2 \%$, respectively) compared to older dogs. In faecal samples from cats, stages of Giardia spp. (12.6\%), Toxocara cati (4.7\%), Toxascaris leonina (0.1\%), Ancylostoma tubaeforme (0.2\%), Aelurostrongylus abstrusus (0.5\%), Capillaria spp. (1.0\%), Taeniidae (0.6\%), Dipylidium caninum (<0.1\%) Mesocestoides spp. (<0.1\%), Isospora spp. (6.0\%), I. felis (4.4\%), I. rivolta (2.2\%), Toxoplasma gondii/Hammondia hammondi $(0.8 \%)$ and Sarcocystis spp. $(0.3 \%)$ were detected. Cats in the age groups up to 3 months and $>3$ up to 6 months of age showed significantly higher infection rates with Giardia spp. (19.5\% and $24.0 \%$, respectively), T. cati ( $8.1 \%$ and $6.9 \%$, respectively), Isospora spp. (12.8\% and 8.6\%, respectively), I. felis (10.0\% and 5.9\%, respectively) and I. rivolta ( $4.6 \%$ and $2.9 \%$, respectively) compared to older cats. 


\section{Introduction}

Dogs and cats are frequently infected with various helminth and protozoan endoparasites. In particular the vertical transmission of Toxocara spp., the intrauterine in dogs and the transmammary in cats, ensures a high infection rate of the offspring. But also protozoan parasites such as Giardia spp. and Isospora spp. are often found in young animals, due to high infection pressure during breeding and a low immunological competence of the newborn offspring. These parasites pose a threat to the health of animals and some of them also to humans. Veterinarians and pet owners have the responsibility to take care for these conditions, and apply appropriate measures to protect the animals and also humans. However, one of the major problems in parasite control is the low awareness of the owners and a variable perception of their responsibility to adequately acting for this situation. Responsible owners usually care for their pets and consult veterinarians to get appropriate advice as well as treatment and prevention measures. Such advice should be evidence-based, either on the results of an individual diagnosis or on knowledge of the parasite prevalence in a population. Retrospective data analysis of the results from diagnostic laboratories is one option to provide such information and is a worthwhile tool to allow assessment of parasite prevalence. However, such data may represent only the group of concerned pet owners who care appropriately for their pet by consulting veterinarians and getting samples analysed. Another weakness of such data analysis is the fact that parasitological examinations in diagnostic laboratories are usually cross-sectional studies. Samples are taken at one individual point in time, which may underestimate the true parasite prevalence. Sager et al. (2006) have demonstrated that parasite prevalence is usually much higher in dogs examined in a longitudinal study compared to crosssectional studies. In addition, the type of the subpopulation of which such data are collected will have an influence on the results. Data analysis performed in animals which are well cared and kept under control measures may yield in lower prevalence data compared to populations with less care and no control measures such as stray animals or pet shelter animals before they are appropriately treated. Martinez-Carrasco et al. (2007) demonstrated that in pet shelter population higher parasite prevalence occur compared to a well cared population. Even if all these shortfalls are taken into consideration, it is still important that large-scale retrospective studies are performed and published in order to allow evidence-based assessment of parasite prevalence and appropriate measures in terms of pet owner education and respective veterinary care.

\section{Materials and methods}

\section{Study population}

Between January 2003 and December 2010 faecal samples from 24,677 dogs (Tab. 1) and 8,560 cats from Germany had been submitted to the commercial Veterinary Laboratory Freiburg for parasitological examination. Samples were obtained from privately owned dogs and cats presented at local veterinary surgeons from all parts of Germany for either gastrointestinal disorders, routine examination and animal vaccination, general health check or without specified reason. Age data of 6,627 examined cats (Tab. 2) and 21,516 dogs provided the basis to analyse the age dependence of the determined infection rates.

\section{Faecal examination}

All specimens were tested by a standardised flotation method with a saturated salt solution with zinc chloride and sodium chloride (specific gravity 1.3). For detecting Giardia spp., all samples were analysed by a coproantigen ELISA (ProSpecT ${ }^{\circledR}$ Giardia Microplate Assay, Remel Europe Ltd., distributed by Sekisui Virotech GmbH, Germany) or sodium acetate formaldehyde SAF technique (Marti and Escher 1990) to concentrate cysts of Giardia. Depending on the quantity of material, the faeces were additionally examined by sedimentation and a 
Tab. 1 Number of coproscopically examined dogs and cats between 2003 and 2010

\begin{tabular}{|c|c|c|}
\hline Year & Number of examined dogs $(\mathbf{n})$ & Number of examined cats $(\mathbf{n})$ \\
\hline 2003 & 2,139 & 755 \\
\hline 2004 & 2,525 & 840 \\
\hline 2005 & 2,608 & 917 \\
\hline 2006 & 2,590 & 960 \\
\hline 2007 & 3,425 & 1,158 \\
\hline 2008 & 3,978 & 1,213 \\
\hline 2009 & 3,709 & 1,208 \\
\hline 2010 & 3,703 & 1,509 \\
\hline $2003-2010$ & 24,677 & 8,560 \\
\hline
\end{tabular}

modified Baermann funnel technique. The results of the coproscopical examinations were recorded and analysed in an excess data bank (Microsoft Access 2007). Infections with I. ohioensis, I. burrowsi and I. neorivolta found in dogs were documented as I. ohioensis-complex. These three protozoan species having smaller oocysts than $I$. canis do not show distinctive morphological criteria in terms of oocyst size or structure and can therefore not be separated by microscopic examination (Lindsay et al. 1997). Due to inadequate morphological characteristics, eggs from the genus Capillaria and from the cestode family Taeniidae were not differentiated.

\section{Statistical analysis}

The data were supplied in electronic form for the statistical analysis. The analysis was performed with the validated programme Testimate Version 6.4 from IDV Gauting (validation of software, hardware and user according to FDA 21 CFR Part 11). All evaluation steps were completely documented. The group differences for dogs and cats concerning age were tested with $\mathrm{Rx} 2$-frequency tables. The null hypothesis was that of no differences $\mathbf{H}_{\mathbf{0}}: \mathbf{p}_{\mathbf{1}}=\mathbf{p}_{\mathbf{2}}=\ldots=\mathbf{p}_{\mathbf{k}}$ (the so-called homogeneity hypothesis). The classical $\mathrm{p}$ values were computed with Pearson without continuity correction and only for smaller samples with the Fisher's exact $\mathrm{p}$ values (two-sided, alpha $=0.05$ ). If the result was significant, two-group comparison for each age group vs. all animals was performed with the Fligner-Wolfe test without any alpha correction for multiple testing. The predefined alpha level two-sided was 0.05 .

\section{Results}

The majority of cats (46.4\%) and dogs (36.1\%) participating in the study were up to one year old (Fig. 1). $7.7 \%$ of the cats and $11.2 \%$ of the dogs were $>1-2$ years old. The percentage of sampled cats and dogs per year decreased in the age groups $>2$ and up to 15 years of age continuously from $5.3 \%$ to $2.0 \%$ per year and $7.6 \%$ to $0.6 \%$

Tab. 2 Number of coproscopically examined dogs and cats with known age between 2003 and 2010

\begin{tabular}{|c|c|c|}
\hline Age group & Number of examined dogs $(\mathbf{n})$ & Number of examined cats $(\mathbf{n})$ \\
\hline$<3$ months & 2,661 & 1,227 \\
\hline$>3-6$ months & 735 & 421 \\
\hline$>6-12$ months & 4,364 & 1,427 \\
\hline$>1-5$ years & 6,489 & 1,360 \\
\hline$>5-10$ years & 4,856 & 1,100 \\
\hline$>10$ years & 2,411 & 1,092 \\
\hline total & 21,516 & 6,627 \\
\hline
\end{tabular}




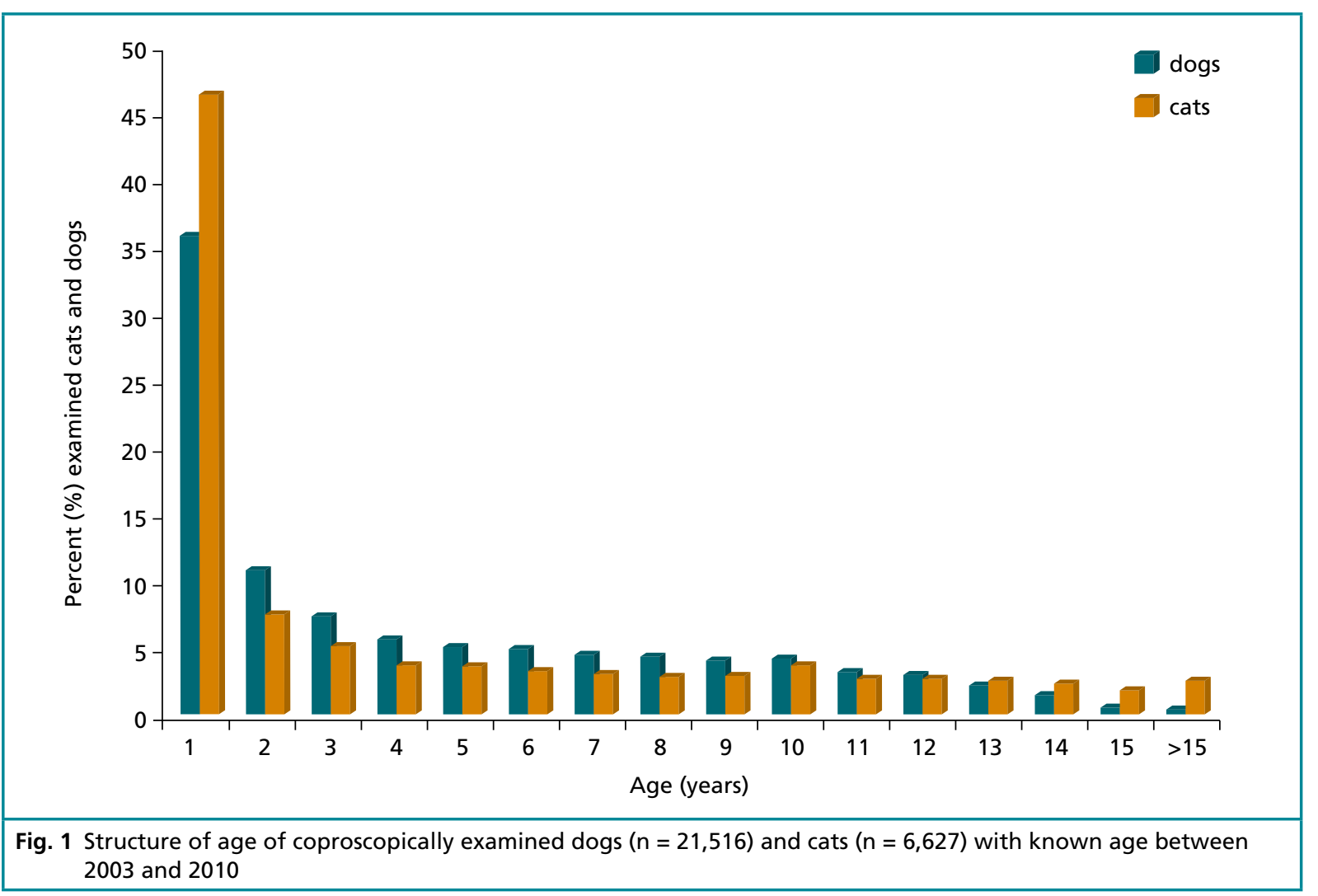

per year, respectively. Cats and dogs older than 15 years were rarely tested for parasites. $30.4 \%$ of the examined dogs were infected with endoparasites. The most commonly parasite found in dogs (Fig. 2) was Giardia spp. (18.6\%), followed by nematodes (10.8\%), coccidia (8.0\%) and cestodes $(0.5 \%)$. The examination of the faecal samples from dogs (Tabs. 3 and 4) revealed infections with Toxocara canis (6.1\%), Toxascaris leonina (0.6\%), Ancylostomatidae (2.2\%), Trichuris vulpis (1.2\%), Capillaria (1.3\%), Crenosoma vulpis (0.4\%), Angiostrongylus vasorum (0.5\%), Taeniidae (0.4\%), Dipylidiidae (<0.1\%), Mesocestoides spp. (<0.1\%), Isospora spp. (5.6\%), I. ohioensis-complex (3.9\%), I. canis (2.4\%), Sarcocystis (2.2\%) and Hammondia heydorni/Neospora caninum (0.3\%). With reference to the prevalence of parasites per year in the period 2003 to 2010 (Tabs. 3 and 4) the determined rates of infection with parasites per year in dogs showed only minor variations.
To analyse the age dependence of infections with endoparasites, dogs with known age have been grouped in six age groups (Figs. 3-5). Dogs in the age groups up to 3 months and $>3$ up to 6 months of age showed significantly higher infection rates ( $<<0.05)$ with Giardia spp. (37.5\% and $38.2 \%$, respectively), Toxocara canis (12.0\% and $12.4 \%$, respectively), Toxascaris leonina (1.1\% and $1.6 \%$, respectively), Isospora spp. (23.4\% and $11.8 \%$, respectively), I. ohioensis-complex (15.6\% and 7.2\%, respectively) and $I$. canis (11.8\% and 5.2\%, respectively) compared to older dogs. The significant highest values $(\mathrm{p}<0.05)$ for Giardia spp., Toxocara canis and Toxascaris leonina were determined in dogs $>3$ months up to 6 months of age, whereas in age groups older than 6 months of age their prevalence rates decreased continuously and stepwise. Significant higher rates $(\mathrm{p}<0.05)$ were determined for Ancylostomatidae and Trichuris vulpis in dogs $>3$ up to 6 months and $>6$ months up to 1 year of age compared to the other age groups. Infections 
with Capillaria spp., Crenosoma vulpis, Angiostrongylus vasorum, cestodes, Sarcocystis spp. and Hammondia heydorni/Neospora caninum indicated only minor changes in prevalence rates and seemed to be equally distributed amongst all age groups. With reference to seasonal variation, eggs of Toxocara canis (Fig. 6) and cysts of Giardia spp. (Fig. 8) in faecal samples were more often found between November and March compared to other months with highest values in January. In contrast to that, infections with Isospora spp. (Fig. 7) were most frequently found in August with continuously decreasing rates until February.

From 8,560 examined cats, a total of $22.8 \%$ proved to be infected with endoparasites. Cysts of Giardia spp. (Fig. 2) were detected in $12.6 \%$, followed by coccidia $(7.0 \%)$, nematodes $(5.9 \%)$ and cestodes ( $0.7 \%)$. Stages of Toxocara cati (Tab. 5) were found in $4.7 \%$, of Toxascaris leonina in $0.1 \%$, of Ancylostoma tubaeforme in $0.2 \%$, of Aelurostrongylus abstrusus in $0.5 \%$, of Capillaria spp. in $1.0 \%$, of Taeniidae in $0.6 \%$, of Dipylidium caninum in $<0.1 \%$, of Mesocestoides spp. in $<0.1 \%$, of
Isospora spp. (Tab. 6) in $6.0 \%$, of I. felis in $4.4 \%$, of I. rivolta in $2.2 \%$, of Toxoplasma gondii/Hammondia hammondi in $0.8 \%$ and of Sarcocystis spp. in $0.3 \%$ of the examined samples. With reference to the prevalence of parasites per year in the period 2003 to 2010 (Tabs. 5 and 6) the determined rates of infection with parasites per year in cats showed only minor variations.

Cats in the age groups up to 3 months and $>3$ up to 6 months of age (Figs. 3, 9 and 10) showed significantly higher infection rates $(\mathrm{p}<0.05)$ with Giardia spp. (19.5\% and $24.0 \%$, respectively), T. cati (8.1\% and $6.9 \%$, respectively), Isospora spp. (12.8\% and $8.6 \%$, respectively), I. felis (10.0\% and $5.9 \%$, respectively) and I. rivolta ( $4.6 \%$ and $2.9 \%$, respectively) compared to older cats. No age-related distribution was seen regarding infections with Toxascaris leonina, Capillaria spp., Aelurostrongylus abstrusus, Ancylostoma tubaeforme, cestodes, Sarcocystis spp. and Toxoplasma gondii/Hammondia hammondi. A seasonal pattern concerning the detection of eggs of T. cati (Fig. 11), cysts of Giardia spp. (Fig. 13) and oocysts of Isospora spp.

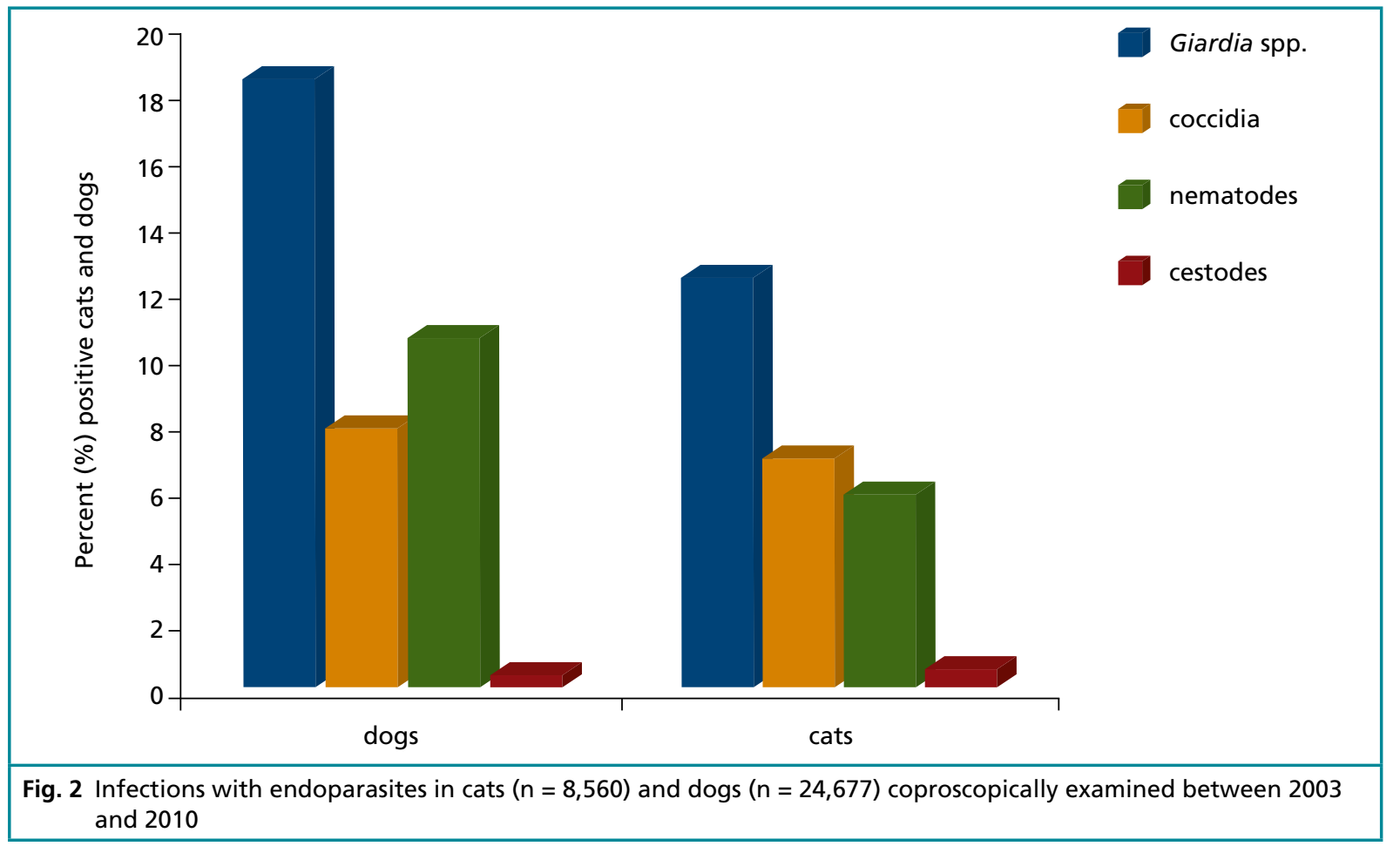



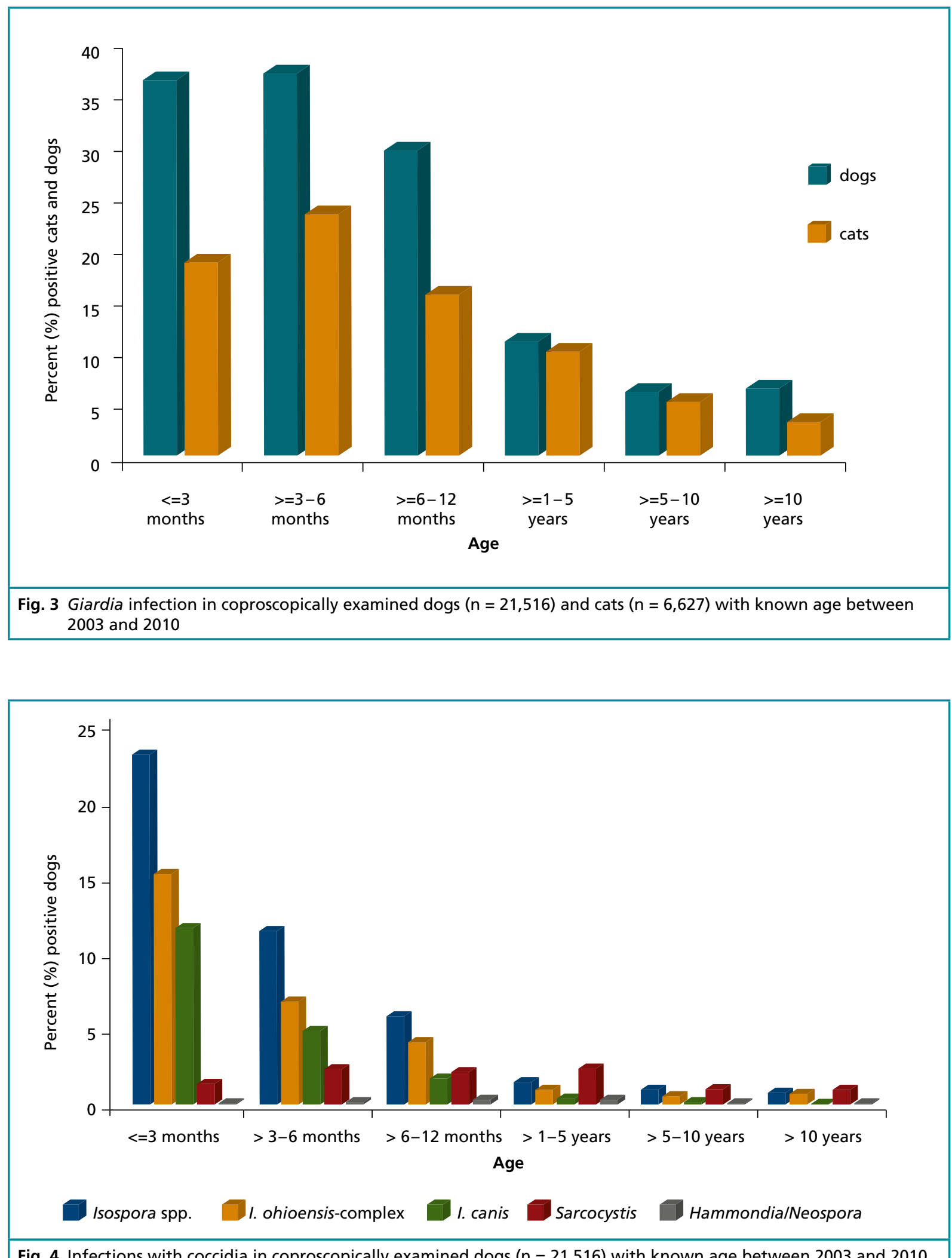

Fig. 4 Infections with coccidia in coproscopically examined dogs $(n=21,516)$ with known age between 2003 and 2010 


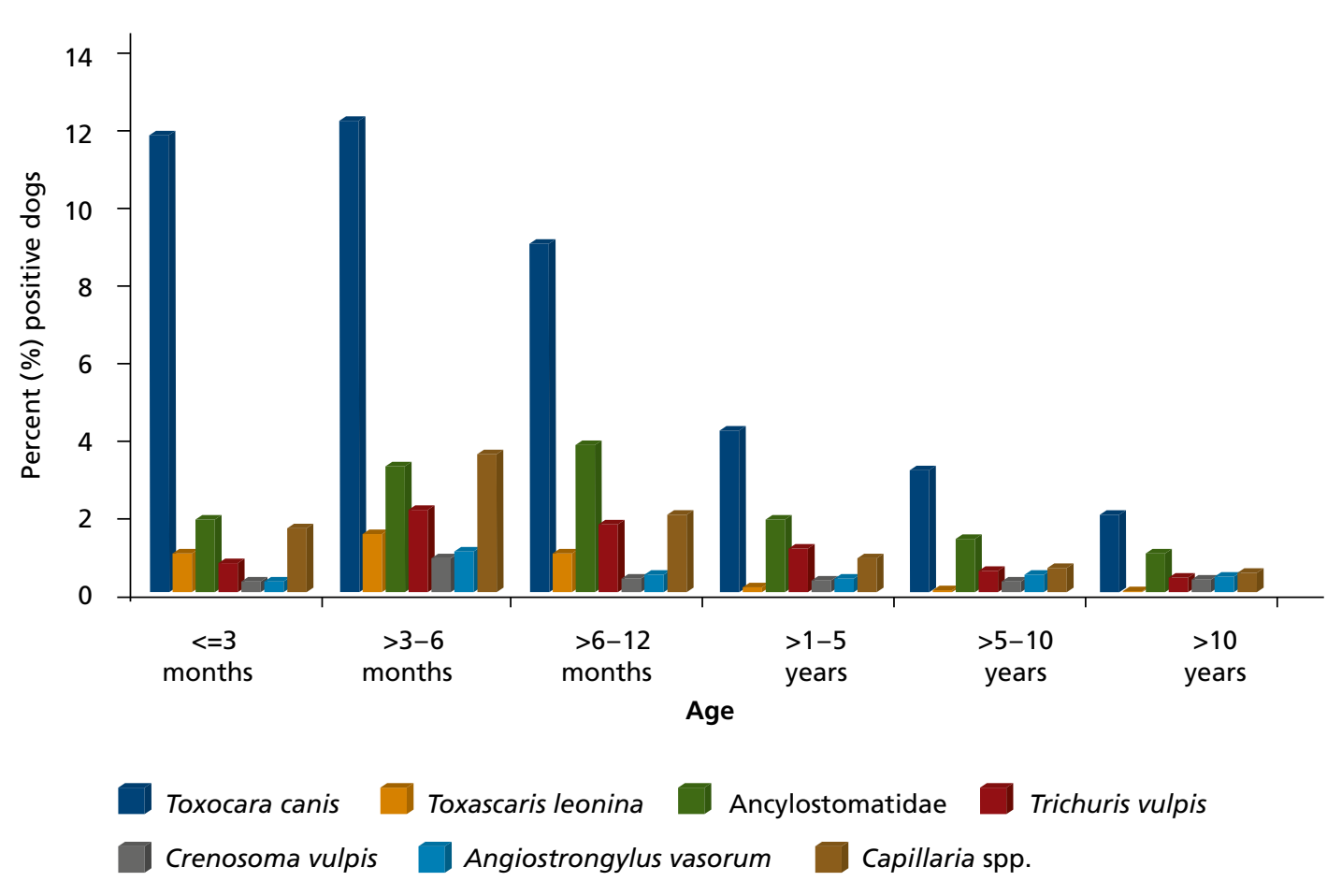

Fig. 5 Infections with nematodes in coproscopically examined dogs $(n=21,516)$ with known age between 2003 and 2010

(Fig. 12) in faecal samples could be demonstrated. T. cati and Giardia spp. were most often found from November until January and October until December, respectively, compared to other months. In contrast to that, infections with Isospora spp. were more frequently found in August and September.

\section{Discussion}

Analyses of results of coproscopical examinations provide an overview about the occurrence and prevalence of endoparasites in dogs and cats. The data presented give an image of the current status of endoparasite infections in pet animals in Germany and the development of parasite prevalence rates within the last eight years. The results are of value to estimate parasite impact and to assist researchers, veterinarians and pet owners with suitable information to control parasites. The monitoring of parasite distribution in the present study demonstrates an unchanged high prevalence of endoparasites in dogs and cats in Germany. $30.4 \%$ of the examined dogs and $22.8 \%$ of the cats proved to be infected with endoparasites. This corresponds almost exactly with the last large-scale analysis done by Barutzki and Schaper (2003), who found $32.2 \%$ of the dogs and $24.3 \%$ of the cats being infected with endoparasites. Over the sample period of the study presented the determined rates of infection with parasites per year in cats and dogs showed only minor variations. That means protozoa, helminths and to a lesser extend cestodes occur frequently, particular in younger dogs and cats. The data presented allow an assessment of the current status of endoparasites in pet animals over a longer period and a comparison to data of other authors in Germany as well as in other European countries. 


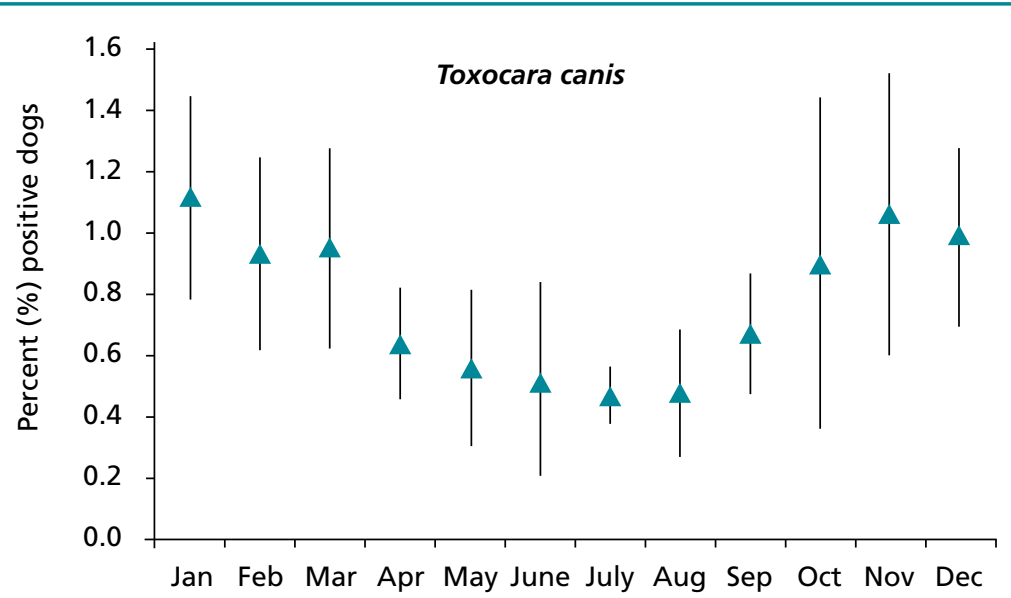

Fig. 6 Seasonal dynamic of Tococara canis in coproscopically examined dogs $(n=24,677)$ between 2003 and 2010

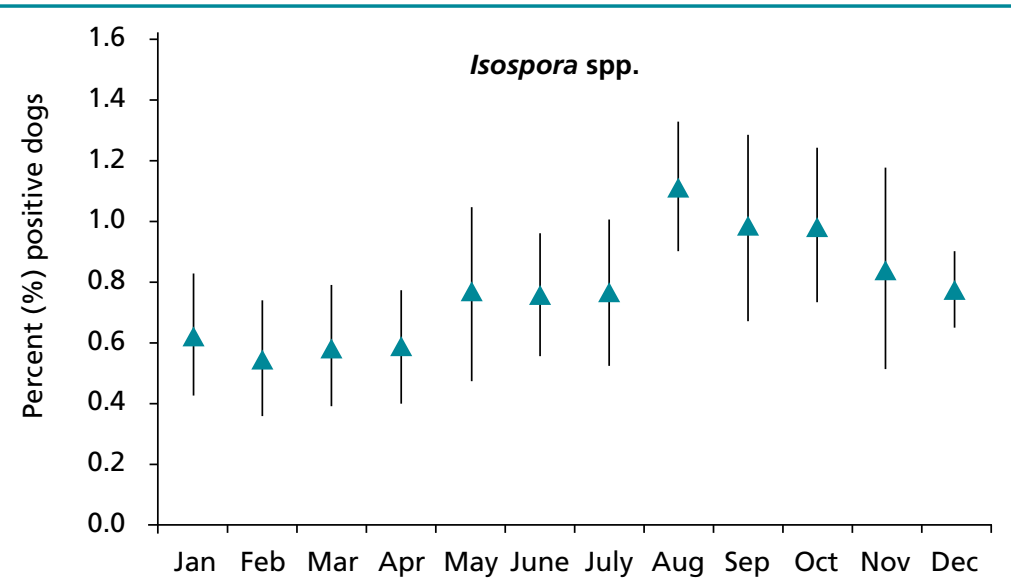

Fig. 7 Seasonal dynamic of Isospora spp. in coproscopically examined dogs $(n=24,677)$ between 2003 and 2010

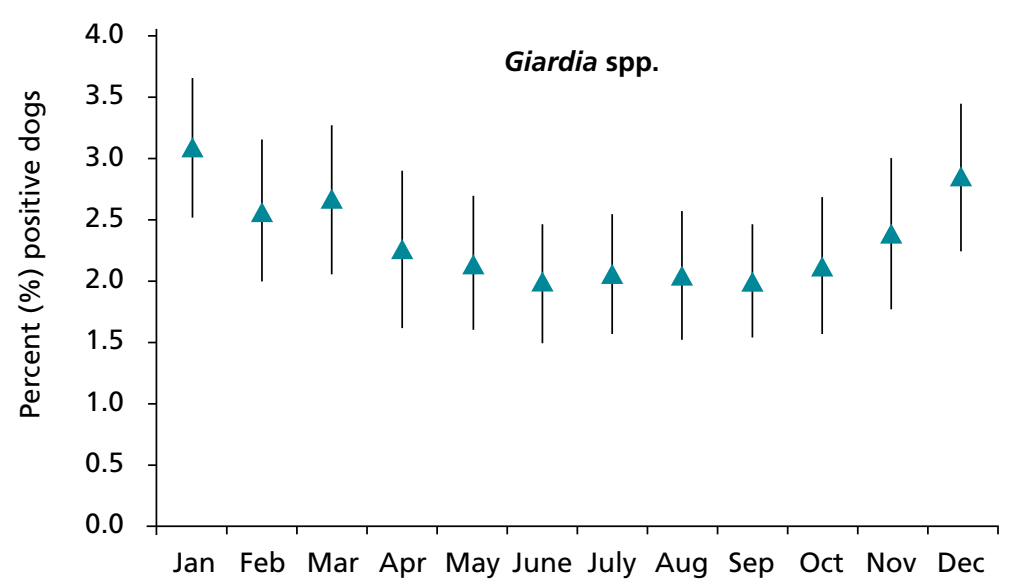

Fig. 8 Seasonal dynamic of Giardia spp. in coproscopically examined dogs $(n=24,677)$ between 2003 and 2010 
Prevalence of endoparasites comparison to other data in Europe

\section{Toxocaridae in dogs}

Gastrointestinal nematodes are endemic in dogs throughout Europe, with T. canis being the most frequently encountered and ubiquitous species. Infection with $T$. canis still appears particularly predominant in young puppies, where it is traditionally estimated that all pups are infected at birth. At least, for this species reasonable data for comparison are available from other European countries. In the study reported here, the prevalence rate of T. canis in dogs was $6.1 \%$ in total, however, in the age groups up to 3 months and $>3$ up to 6 months of age it was $12.0 \%$ and $12.4 \%$, respectively. In a survey carried out in dogs of Murcia in Spain, the prevalence of $T$. canis in dogs $<1$ year old was $20 \%$ compared to $5-11 \%$ for older age groups (Martinez-Carrasco et al. 2007). In a study conducted in Belgium (Claerebout et al. 2009), T. canis were present in $4.4 \%$ of household dogs and $26.3 \%$ of dogs from kennels, whereof around $50 \%$ were pups. In Greece, Haralabidis et al. (1988) reported that $22.4 \%$ of dogs were infected with $T$. canis with the highest prevalence in the up to six-month-old dogs. These results from epidemiological studies in other European countries confirm that infections rates with $T$. canis are considerably higher in puppies and young dogs compared to older dogs.

Results from a study from Fok et al. (2001) suggest higher prevalence rates in some eastern European countries compared to western European countries. The authors reported a prevalence of 24.3-30.1\% $T$. canis in the dog population surveyed, with prevalence in pups aged less than three months of $48.7 \%$. A difference in prevalence rates between urban and rural dogs in the Czech Republic was illustrated by Dubná et al. (2007), where $13.7 \%$ of rural dogs had patent $T$. canis compared with $6.2 \%$ of urban dogs. In Scandinavia, adult Finnish dogs were reported to have a prevalence of $3.1 \% T$. canis and $2.6 \%$ Uncinaria stenocephala (Pullola et al. 2006). These comparative data demonstrate that the infection level with $T$. canis predominantly depends on the age of the dogs but also on keeping conditions of the animals and probably on the living condition of the pet holder, too. The prevalence rate of $T$. canis in the dog population of Germany seems to be somewhat lower compared to other countries. This may result from the subgroup of animals studied, which probably represent dogs of concerned pet owners, being under continuous veterinary control, with a higher degree of care and preventative measures.

\section{Ancylostomatidae in dogs}

In this study, the prevalence rate of Ancylostomatidae in dogs was $2.2 \%$ and corresponds to approximately earlier surveys in Germany (Barutzki and Schaper 2003). Hookworms, particularly A. caninum, may also be seen in young pups where infection is endemic. In a survey of dogs in Murcia in Spain (Martinez-Carrasco et al. 2007), only $0.7 \%$ of pet dogs had evidence of hookworms. In contrast to this, the prevalence of the Ancylostomidae in up to one-year-old dogs was considerably higher and amounted to $6 \%$. According to this, the prevalence rates of hookworms in dogs from Hungary were $8.1-13.1 \%$ and predominant in puppies and young dogs (Fok et al. 2001). In Greece, Haralabidis et al. (1988) reported that hookworms first appeared in dogs aged 6 to 12 months with an overall prevalence of $3 \%$. A survey in Belgium (Claerebout et al. 2009) indicated analogue data with $3 \%$ hookworm infections in kennel dogs. Dubná et al. (2007) reported for the Czech Republic a prevalence of 0.7-0.9\% of hookworms in rural dogs compared to $0.4 \%$ in urban dogs. Pullola et al. (2006) reported a prevalence of $2.6 \%$ for $U$. stenocephala in adult Finnish dogs. Hookworm infections with either Ancylostoma caninum or Uncinaria stenocephala tend to be variable and focused in regional geographic areas. But they represent the second most common nematode in dogs. In the study presented, eggs of hookworms were more frequently found in $\operatorname{dogs}>3$ months up to 1 year of age compared to older and younger dogs. This is an indication that $A$. caninum is not endemic in Germany. Because of the low mean temperature 


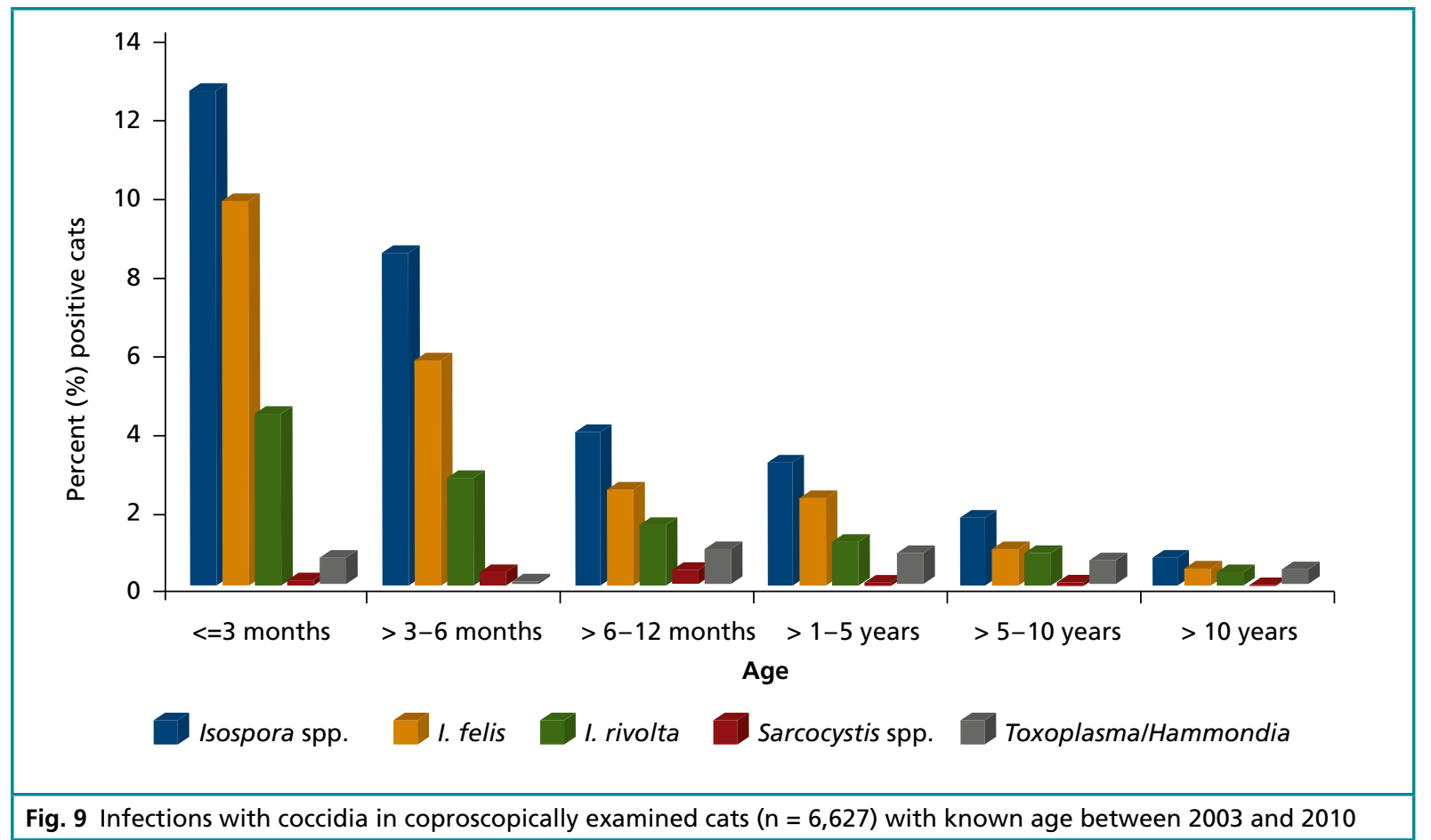

it is most likely that only $U$. stenocephala is common North of the Alps. A. caninum is transmitted by transmammary infection and should lead to higher prevalence rates in young puppies.

\section{Helminths in cats}

In contrast to dogs, much less data are available for cats. In the study reported here, stages of Toxocara cati were found in $4.7 \%$, of Toxascaris leonina in $0.1 \%$, of Ancylostoma tubaeforme in $0.2 \%$ of the examined cats. Compared to a previous survey (Barutzki and Schaper 2003) the prevalence rate of $T$. cati has been slightly declined, whereas the values for the other parasites stayed almost unaltered. Depending on the subpopulation being tested, the occurrence and distribution of $T$. cati in Germany vary considerably. Hecking-Veltman et al. (2001) demonstrated a prevalence of $43.3 \%$ for $T$. cati in stray cats. Similar high levels for shelter cats were confirmed by Rohen (2009), who found $27.1 \%$ of cats positive for T.cati. In a multicentre study, Coati et al. (2003) found eggs from T. cati in $11.6 \%$ of the examined samples. In contrast to that, the results of routinely done parasitological examination of cats at the Institute for Parasitology, University of Veterinary Medicine Hannover, showed only 3.9\% T. catipositive samples (Epe et al. 2004). Prevalence rates of $A$. tubaeforme and tapeworms did rarely exceed $1 \%$, however, in stray cats these were $2 \%$ for hookworms and $4.1 \%$ for tapeworms (Hecking-Veltman et al. 2001). This level was confirmed in shelter cats by Rohen (2009), who found $1.1 \%$ hookworm-positive cats and Taeniidae in $2.0 \%$ of the cats.

\section{Giardia spp.}

In this study, the most commonly found parasite in dogs and cats was Giardia spp. (18.6\% and $12.6 \%$, respectively). This confirms the high prevalence rates of Giardia spp. published in a previous study (Barutzki and Schaper 2003). For Germany, a number of studies have been performed more recently and provide a robust data basis for comparison. Beelitz et al. (2006) found Giardia spp. in $40.2 \%$ of dogs kept in groups and in $27.6 \%$ of dogs kept individually in southern Germany. Heusinger (2007) analysed commercial lab data and confirmed 


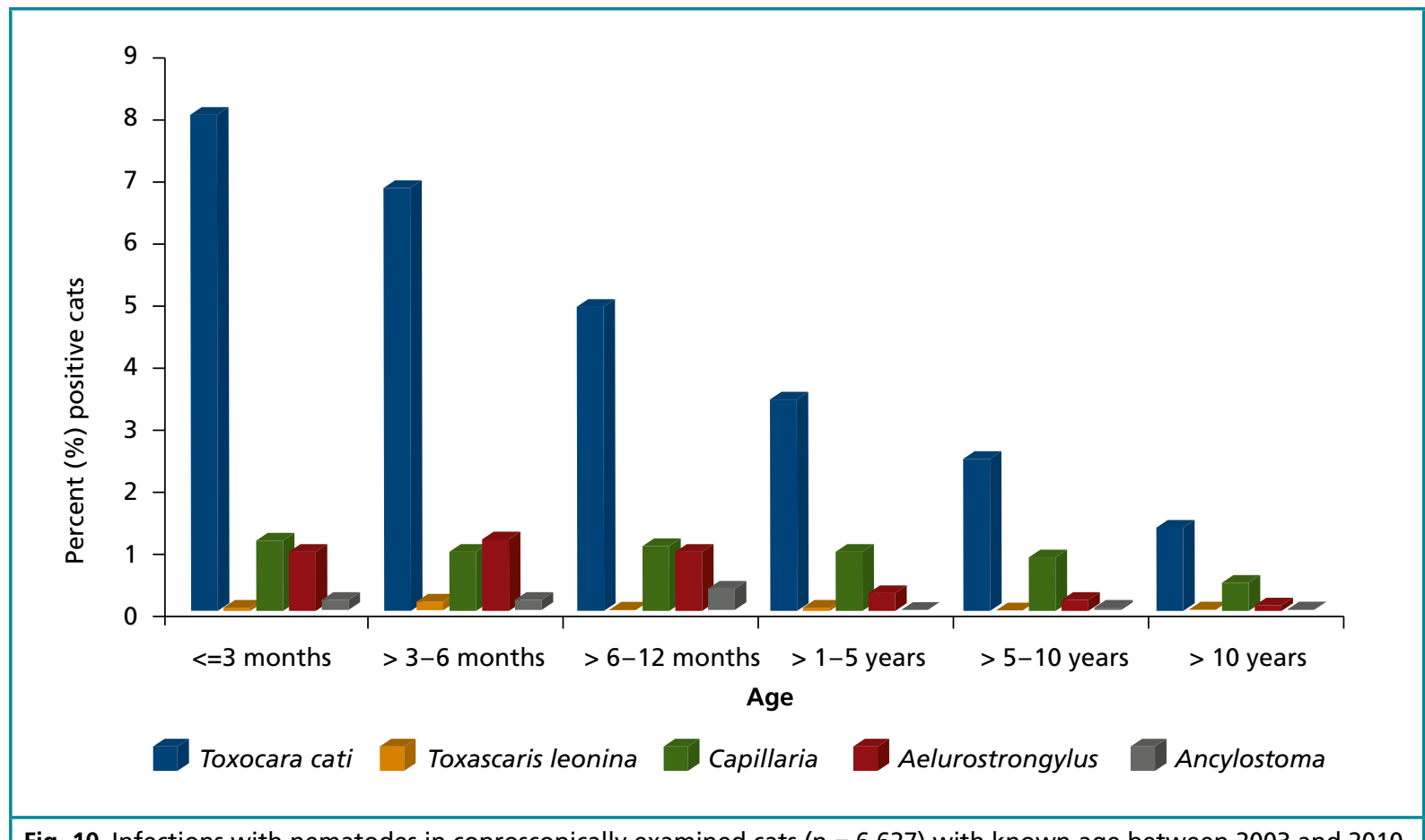

Fig. 10 Infections with nematodes in coproscopically examined cats $(n=6,627)$ with known age between 2003 and 2010

a high prevalence of Giardia spp. in dogs, however, with variable results depending on the method used. Testing by ELISA revealed an average infection rate of $20.58 \%$ and with flotation method only of $8.05 \%$. For the UK, Batchelor et al. (2008) reportet an infection rate of $8.4 \%$ in dogs and a significantly higher rate of $16.3 \%$ in dogs under 12 months of age. Upjohn et al. (2010) investigated Giardia spp. prevalence in Central London shelter dogs and found an infection rate of $21 \%$. In Belgium, Claerbout et al. (2009) investigated the prevalence of endoparasites in different dog populations. In kennel dogs, the prevalence of Giardia spp. was $43.9 \%$, in household dogs only $9.3 \%$. Dogs with gastrointestinal symptoms showed a prevalence of $18.1 \%$. In Italy, Scaramozzino et al. (2009) investigated the prevalence of Giardia spp. in dogs in kennels and found a rate of $20.5 \%$.

In a recent large scale analysis of cross-sectional data from commercial laboratories, Epe et al. (2010) confirmed a high prevalence of Giardia spp. across a number of different European countries. In dogs, prevalence of Giardia spp. was $28.47 \%$ for
Belgium, $23.75 \%$ for Germany, $25.10 \%$ for Spain, $27.53 \%$ for France, $25.89 \%$ for Italy, $24.62 \%$ for the Netherlands and $14.62 \%$ for the UK. These comprehensive data support the findings of this study: Giardia spp. is the most prevalent endoparasite in dogs across a number of European countries. Due to the zoonotic potential of this parasite, an ongoing surveillance of the prevalence is warranted. In this study, also data from cats were published. The prevalence was $26.32 \%$ for Belgium, $24.59 \%$ for Germany, $14.59 \%$ for Spain, $15.31 \%$ for France, $17.71 \%$ for Italy, $13.20 \%$ for the Netherlands and $11.54 \%$ for the UK.

\section{Coccidia}

In dogs, coccida were the third most prevalent parasite group in dogs with a rate of $8 \%$, however, with a prevalence of Isospora spp. in the age group up to 3 months of age of $23.4 \%$ and $>3-6$ months of age of $11.8 \%$. In cats the corresponding figures for Isospora spp. were $6.0 \%$ overall, cats up to 3 months of age and $>3$ months up to 6 months of age showed significantly higher infection rates 


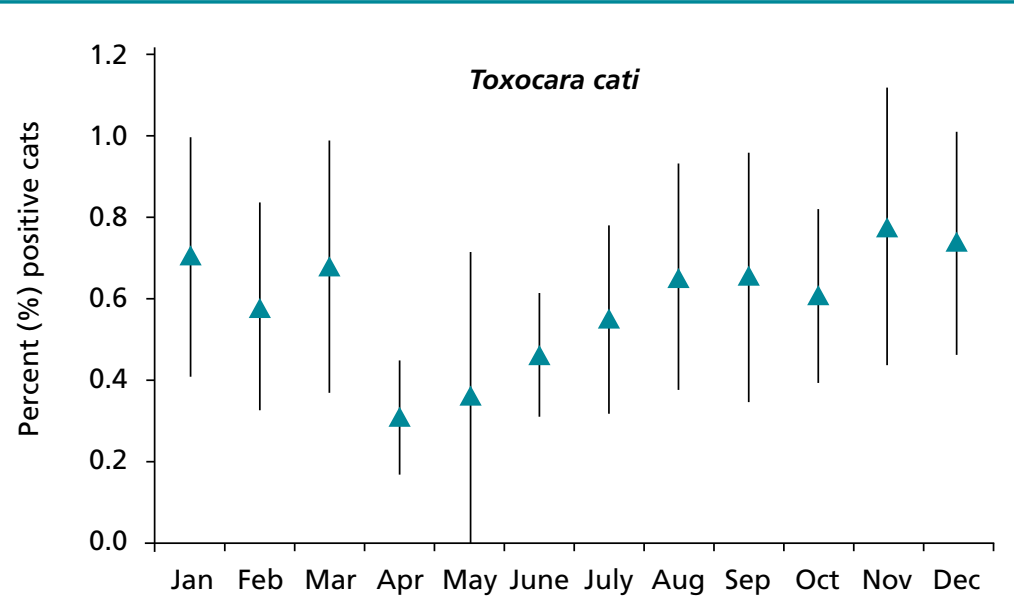

Fig. 11 Seasonal dynamic of Toxocara cati in coproscopically examined cats ( $n=8,560$ ) between 2003 and 2010

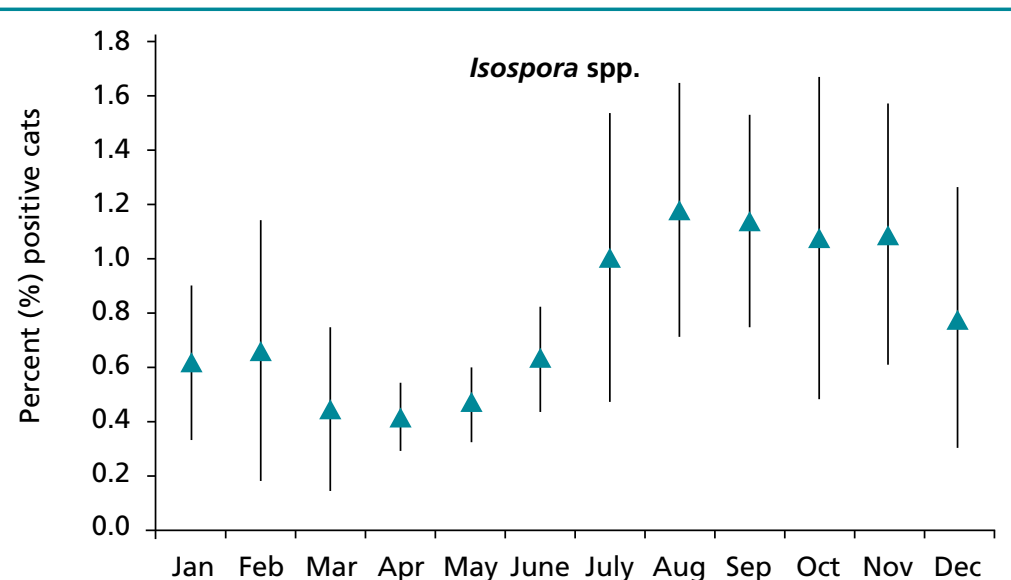

Fig. 12 Seasonal dynamic of Isospora spp. in coproscopically examined cats $(n=8,560)$ between 2003 and 2010

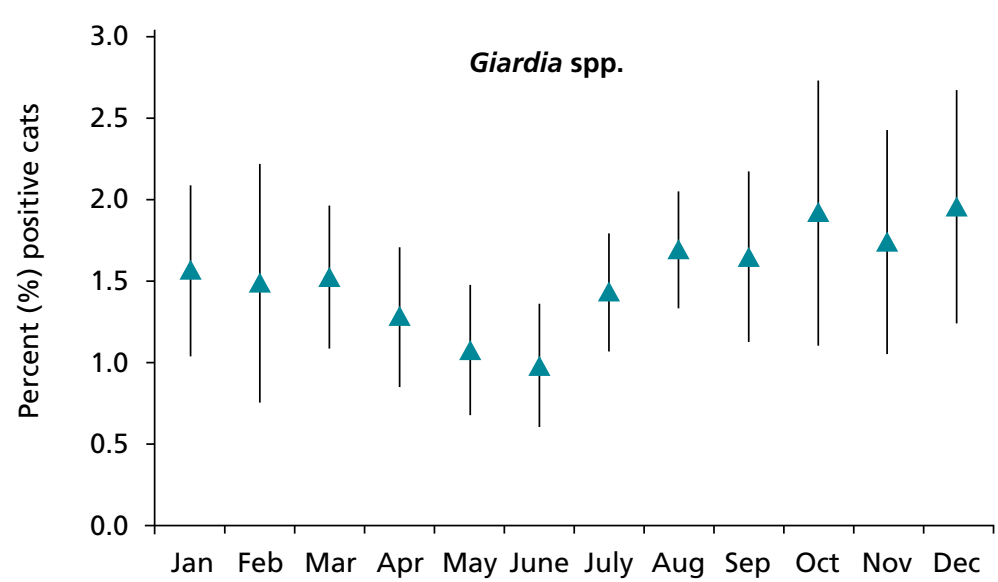

Fig. 13 Seasonal dynamic of Giardia spp. in coproscopically examined cats $(n=8,560)$ between 2003 and 2010 
Tab. 3 Number $(n)$ and percent (\%) of helminth-positive dogs found by coproscopical examination from 2003-2010 in Germany

\begin{tabular}{|c|c|c|c|c|c|c|c|c|c|c|c|c|c|c|c|}
\hline \multirow[t]{2}{*}{ Year } & \multirow[t]{2}{*}{$\begin{array}{l}\text { Number of } \\
\text { examined } \\
\text { dogs }\end{array}$} & \multicolumn{2}{|c|}{$\begin{array}{l}\text { Toxocara } \\
\text { canis } \\
\text { number/ } \\
\text { share } \\
\text { positive } \\
\text { dogs }\end{array}$} & \multicolumn{2}{|c|}{$\begin{array}{c}\text { Toxascaris } \\
\text { leonina } \\
\text { number/ } \\
\text { share } \\
\text { positive } \\
\text { dogs }\end{array}$} & \multicolumn{2}{|c|}{$\begin{array}{l}\text { Ancylostomi- } \\
\text { dae } \\
\text { number/ } \\
\text { share } \\
\text { positive } \\
\text { dogs }\end{array}$} & \multicolumn{2}{|c|}{$\begin{array}{l}\text { Trichuris } \\
\text { vulpis } \\
\text { number/ } \\
\text { share } \\
\text { positive } \\
\text { dogs }\end{array}$} & \multicolumn{2}{|c|}{$\begin{array}{l}\text { Crenosoma } \\
\text { vulpis } \\
\text { number/ } \\
\text { share } \\
\text { positive } \\
\text { dogs }\end{array}$} & \multicolumn{2}{|c|}{$\begin{array}{c}\text { Angio- } \\
\text { strongylus } \\
\text { vasorum } \\
\text { number/ } \\
\text { share } \\
\text { positive } \\
\text { dogs }\end{array}$} & \multicolumn{2}{|c|}{$\begin{array}{c}\text { Capillaria } \\
\text { number/ } \\
\text { share } \\
\text { positive } \\
\text { dogs }\end{array}$} \\
\hline & & (n) & (\%) & (n) & (\%) & (n) & (\%) & (n) & (\%) & (n) & (\%) & (n) & (\%) & (n) & (\%) \\
\hline 2003 & 2,139 & 147 & 6.9 & 15 & 0.7 & 42 & 2.0 & 33 & 1.5 & 3 & 0.1 & 1 & 0.1 & 37 & 1.7 \\
\hline 2004 & 2,525 & 143 & 5.7 & 13 & 0.5 & 43 & 1.7 & 34 & 1.3 & 4 & 0.2 & 2 & 0.1 & 20 & 0.8 \\
\hline 2005 & 2,608 & 135 & 5.2 & 20 & 0.8 & 46 & 1.8 & 25 & 1.0 & 4 & 0.2 & 4 & 0.2 & 24 & 0.9 \\
\hline 2006 & 2,590 & 148 & 5.7 & 11 & 0.4 & 55 & 2.1 & 24 & 0.9 & 9 & 0.3 & 4 & 0.2 & 39 & 1.5 \\
\hline 2007 & 3,425 & 220 & 6.4 & 15 & 0.4 & 69 & 2.0 & 46 & 1.3 & 13 & 0.4 & 16 & 0.5 & 52 & 1.5 \\
\hline 2008 & 3,978 & 284 & 7.1 & 29 & 0.7 & 111 & 2.8 & 53 & 1.3 & 31 & 0.8 & 38 & 1.0 & 68 & 1.7 \\
\hline 2009 & 3,709 & 215 & 5.8 & 15 & 0.4 & 88 & 2.4 & 40 & 1.1 & 21 & 0.6 & 31 & 0.8 & 44 & 1.2 \\
\hline 2010 & 3,703 & 223 & 6.0 & 19 & 0.5 & 84 & 2.3 & 37 & 1.0 & 16 & 0.4 & 32 & 0.9 & 35 & 0.9 \\
\hline $2003-2010$ & 24,677 & 1,515 & 6.1 & 137 & 0.6 & 538 & 2.2 & 292 & 1.2 & 101 & 0.4 & 128 & 0.5 & 319 & 1.3 \\
\hline
\end{tabular}

with Isospora spp. at $12.8 \%$ and $8.6 \%$, respectively. This corresponds with the results of a similar study conducted previously (Barutzki and Schaper 2003). Data about coccidian prevalence in Europe are scarcely published. Most of the studies have shown that puppies and young animals are more likely infected with protozoa than older dogs and cats (Daugschies et al. 2000; Barutzki and Schaper 2003; Buehl et al. 2006). These high prevalence data in especially young animals demonstrate that coccidia are frequently found and likely pose a higher thread to the animals than previously thought.

A seasonal pattern was noticed for the excretion of cysts of Giardia spp., eggs of T. canis and T. cati and oocysts of Isospora spp. of cats and dogs. A peak of infection with Giardia spp. was found in January for dogs and in December for cats. Eggs of $T$. canis and T. cati were mostly found from November till January and oocysts of Isospora spp. from dogs and cats in August. The reason for this phenomenon is unknown but was already described by Batchelor et al. (2008) for I. canis. Further work would be necessary to determine if these seasonal patterns are constant.

\section{Lungworms}

In terms of lungworm infections in dogs there seems to be an increasing trend, supported by data from a similar study conducted by Barutzki and Schaper (2009). Compared to a previous study (Barutzki and Schaper 2003), the prevalence rates of Capillaria spp. have been raised from $0.7 \%$ to $1.3 \%$, of Crenosoma vulpis from $0.3 \%$ to $0.4 \%$, and of Angiostrongylus vasorum from $0.1 \%$ to $0.5 \%$ whereas the rate of Aelurostrongylus abstrusus in cats decreased from $0.7 \%$ to $0.5 \%$. Although the infection rates are still relatively low overall, this fact is somewhat surprising and may indicate a further spread of lungworm parasites in dogs, as it was also discussed in more recent studies performed in Germany by Barutzki and Schaper (2009) and Taubert et al. (2009).

\section{Cestodes}

Stages of tapeworms belonging to the family Taeniidae, Dipylidiidae and the genus Mesocestoides were only accidentally found. The results presented for dogs and cats document percentages not exceeding a rate of $1 \%$. These low values determined by faecal examination do not represent the 
Tab. 4 Number (n) and percent (\%) of protozoa-positive dogs found by coproscopical examination from 2003-2010 in Germany

\begin{tabular}{|c|c|c|c|c|c|c|c|c|c|c|c|c|c|}
\hline \multirow[t]{2}{*}{ Year } & \multirow[t]{2}{*}{$\begin{array}{l}\text { Number } \\
\text { of } \\
\text { examined } \\
\text { dogs }\end{array}$} & \multicolumn{2}{|c|}{$\begin{array}{l}\text { Isospora spp. } \\
\text { number/ } \\
\text { share } \\
\text { positive dogs }\end{array}$} & \multicolumn{2}{|c|}{\begin{tabular}{|l|} 
I. ohioensis- \\
complex \\
number/ \\
share \\
positive dogs
\end{tabular}} & \multicolumn{2}{|c|}{$\begin{array}{c}\text { I. canis } \\
\text { number/ } \\
\text { share } \\
\text { positive dogs }\end{array}$} & \multicolumn{2}{|c|}{$\begin{array}{l}\text { Hammondia/ } \\
\text { Neospora } \\
\text { number/ } \\
\text { share } \\
\text { positive dogs }\end{array}$} & \multicolumn{2}{|c|}{$\begin{array}{l}\text { Sarcocystis } \\
\text { number/ } \\
\text { share } \\
\text { positive dogs }\end{array}$} & \multicolumn{2}{|c|}{$\begin{array}{l}\text { Giardia spp. } \\
\text { number/ } \\
\text { share } \\
\text { positive dogs }\end{array}$} \\
\hline & & (n) & $(\%)$ & (n) & $(\%)$ & (n) & $(\%)$ & (n) & $(\%)$ & (n) & $(\%)$ & (n) & $(\%)$ \\
\hline 2003 & 2,139 & 136 & 6.4 & 100 & 4.7 & 49 & 2.3 & 12 & 0.6 & 34 & 1.6 & 375 & 17.5 \\
\hline 2004 & 2,525 & 155 & 6.1 & 103 & 4.1 & 68 & 2.7 & 6 & 0.2 & 60 & 2.4 & 518 & 20.5 \\
\hline 2005 & 2,608 & 181 & 6.9 & 121 & 4.6 & 79 & 3.0 & 7 & 0.3 & 73 & 2.8 & 525 & 20.1 \\
\hline 2006 & 2,590 & 154 & 5.9 & 113 & 4.4 & 66 & 2.5 & 11 & 0.4 & 61 & 2.4 & 481 & 18.6 \\
\hline 2007 & 3,425 & 205 & 6.0 & 147 & 4.3 & 92 & 2.7 & 9 & 0.3 & 71 & 2.1 & 705 & 20.6 \\
\hline 2008 & 3,978 & 198 & 5.0 & 131 & 3.3 & 91 & 2.3 & 10 & 0.3 & 95 & 2.4 & 650 & 16.3 \\
\hline 2009 & 3,709 & 179 & 4.8 & 130 & 3.5 & 70 & 1.9 & 12 & 0.3 & 74 & 2.0 & 698 & 18.8 \\
\hline 2010 & 3,703 & 183 & 4.9 & 128 & 3.5 & 73 & 2.0 & 13 & 0.4 & 74 & 2.0 & 639 & 17.3 \\
\hline $2003-2010$ & 24,677 & 1,391 & 5.6 & 973 & 3.9 & 588 & 2.4 & 80 & 0.3 & 542 & 2.2 & 4,591 & 18.6 \\
\hline
\end{tabular}

true prevalence as demonstrated by a comparison of coproscopical and post-mortem examinations in dogs. By means of coproscopical examination $1 \%$ cestode-positive dogs were determined, whereas in the same population necropsy revealed $47 \%$ tapeworm-infected dogs (Martinez-Carrasco et al. 2007). The discrepancy between coproscopical and post-mortem examination is due to the excretion behaviour of cestodes. Eggs packets of Dipylidium caninum are seldom seen free in faeces. They might be expressed from the gravid proglottid, but in general, mature proglottids are released from the tapeworm's posterior end and leave the host in faeces passively or even by active emigration passing the faeces without maceration. Also proglottides of Taeniidae are motile and they represent the diagnostic stage, which may be found on the surface of faeces. This holds true for Mesocestoides, whose eggs are stored in the paruterine organ. The whole proglottid is the diagnostic stage, which is seldom seen in the faeces. Therefore, it can be concluded that the real prevalence of tapeworm infections in dogs and cats is certainly much higher than documented in the present study.

Tab. 5 Number $(n)$ and percent (\%) of helminth-positive cats found by coproscopical examination from 2003-2010 in Germany

\begin{tabular}{|c|c|c|c|c|c|c|c|c|c|c|c|}
\hline \multirow[t]{2}{*}{ Year } & \multirow[t]{2}{*}{$\begin{array}{c}\text { Number } \\
\text { of } \\
\text { exam- } \\
\text { ined } \\
\text { cats }\end{array}$} & \multicolumn{2}{|c|}{$\begin{array}{c}\text { Toxocara cati } \\
\text { number/share } \\
\text { positive cats }\end{array}$} & \multicolumn{2}{|c|}{$\begin{array}{c}\text { Toxascaris } \\
\text { leonina } \\
\text { number/share } \\
\text { positive cats }\end{array}$} & \multicolumn{2}{|c|}{$\begin{array}{l}\text { Ancylostoma } \\
\text { tubaeforme } \\
\text { number/share } \\
\text { positive cats }\end{array}$} & \multicolumn{2}{|c|}{$\begin{array}{c}\text { Aelurostrongylus } \\
\text { abstrusus } \\
\text { number/share } \\
\text { positive cats }\end{array}$} & \multicolumn{2}{|c|}{$\begin{array}{c}\text { Capillaria } \\
\text { number/share } \\
\text { positive cats }\end{array}$} \\
\hline & & (n) & (\%) & (n) & $(\%)$ & (n) & $(\%)$ & (n) & (\%) & (n) & (\%) \\
\hline 2003 & 755 & 43 & 5.7 & 0 & 0 & 1 & 0.1 & 3 & 0,4 & 16 & 2.1 \\
\hline 2004 & 840 & 45 & 5.4 & 0 & 0 & 1 & 0.1 & 0 & 0 & 13 & 1.5 \\
\hline 2005 & 917 & 56 & 6.1 & 2 & 0.2 & 0 & 0 & 4 & 0.4 & 9 & 1.0 \\
\hline 2006 & 960 & 45 & 4.7 & 1 & 0.1 & 0 & 0 & 2 & 0.2 & 7 & 0.7 \\
\hline 2007 & 1,158 & 59 & 5.1 & 1 & 0.1 & 4 & 0.3 & 6 & 0.5 & 18 & 1.6 \\
\hline 2008 & 1,213 & 32 & 2.6 & 2 & 0.2 & 2 & 0.2 & 9 & 0.7 & 8 & 0.7 \\
\hline 2009 & 1,208 & 44 & 3.6 & 1 & 0.1 & 3 & 0.2 & 8 & 0.7 & 7 & 0.6 \\
\hline 2010 & 1,509 & 77 & 5.1 & 1 & 0.1 & 3 & 0.2 & 13 & 0.9 & 4 & 0.3 \\
\hline $2003-2010$ & 8,560 & 401 & 4.7 & 8 & 0.1 & 14 & 0.2 & 45 & 0.5 & 82 & 1.0 \\
\hline
\end{tabular}


Tab. 6 Number (n) and percent (\%) of protozoa-positive cats found by coproscopical examination from 2003-2010 in Germany

\begin{tabular}{|c|c|c|c|c|c|c|c|c|c|c|c|c|c|}
\hline \multirow[t]{2}{*}{ Year } & \multirow{2}{*}{$\begin{array}{c}\text { Number } \\
\text { of } \\
\text { exam- } \\
\text { ined } \\
\text { cats }\end{array}$} & \multicolumn{2}{|c|}{$\begin{array}{l}\text { Isospora spp. } \\
\text { number/share } \\
\text { positive cats }\end{array}$} & \multicolumn{2}{|c|}{$\begin{array}{c}\text { I. rivolta } \\
\text { number/share } \\
\text { positive cats }\end{array}$} & \multicolumn{2}{|c|}{$\begin{array}{c}\text { I. felis } \\
\text { number/share } \\
\text { positive cats }\end{array}$} & \multicolumn{2}{|c|}{$\begin{array}{l}\text { Toxoplasma/ } \\
\text { Hammondia } \\
\text { number/share } \\
\text { positive cats }\end{array}$} & \multicolumn{2}{|c|}{$\begin{array}{c}\text { Sarcocystis } \\
\text { number/share } \\
\text { positive cats }\end{array}$} & \multicolumn{2}{|c|}{$\begin{array}{l}\text { Giardia spp. } \\
\text { number/share } \\
\text { positive cats }\end{array}$} \\
\hline & & (n) & $(\%)$ & (n) & $(\%)$ & (n) & $(\%)$ & (n) & $(\%)$ & (n) & $(\%)$ & (n) & $(\%)$ \\
\hline 2003 & 755 & 44 & 5.8 & 26 & 3.4 & 25 & 3.3 & 4 & 0.5 & 2 & 0.3 & 96 & 12.7 \\
\hline 2004 & 840 & 51 & 6.1 & 14 & 1.7 & 42 & 5.0 & 4 & 0.5 & 0 & 0 & 90 & 10.7 \\
\hline 2005 & 917 & 60 & 6.5 & 20 & 2.2 & 45 & 4.9 & 13 & 1.4 & 4 & 0.4 & 124 & 13.5 \\
\hline 2006 & 960 & 54 & 5.6 & 22 & 2.3 & 36 & 3.8 & 7 & 0.7 & 8 & 0.8 & 134 & 14.0 \\
\hline 2007 & 1,158 & 77 & 6.6 & 22 & 1.9 & 60 & 5.2 & 13 & 1.1 & 4 & 0.3 & 159 & 13.7 \\
\hline 2008 & 1,213 & 65 & 5.4 & 19 & 1.6 & 51 & 4.2 & 8 & 0.7 & 4 & 0.3 & 156 & 12.9 \\
\hline 2009 & 1,208 & 65 & 5.4 & 22 & 1.8 & 44 & 3.6 & 9 & 0.7 & 2 & 0.2 & 164 & 13.6 \\
\hline 2010 & 1,509 & 96 & 6.4 & 46 & 3.0 & 72 & 4.8 & 8 & 0.5 & 4 & 0.3 & 159 & 10.5 \\
\hline $2003-2010$ & 8,560 & 512 & 6.0 & 191 & 2.2 & 375 & 4.4 & 66 & 0.8 & 28 & 0.3 & 1,082 & 12.6 \\
\hline
\end{tabular}

\section{Conclusion}

In Germany, endoparasites in dogs and cats still remain on a considerable high level, especially compared to a similar study conducted previously by the same authors. In this study, for the first time a detailed age-dependant analysis could be accomplished, presenting the high level of parasite infections especially in the age group up to three months, and $>3-6$ months of age. This highlights even more the need for parasite control, supported by veterinarians and organisations such as the European Scientific Counsel Companion Animal Parasites. Taking into consideration the shortfalls of a cross-sectional study and the fact that data from a well-cared population have been analysed, it may be concluded that the true prevalence in the average population is on a substantially higher level. Thus it is evident, that the veterinary profession must not forget this important aspect of animal welfare, when caring for their patients and advising their owners accordingly. Performance of such studies indicating stable or even increasing parasite prevalence rates is delivering robust data to take evidence-based decisions and highlight the need for further efforts in the control of parasites. The experiences of the last years demonstrate that despite detailed knowledge of the parasites life cycles, proved disinfectant and hygiene measures, various routes of transmission and high tenacity of exogenous stages ensure the survival and maintenance of parasites.

\section{Acknowledgements}

We thank Dipl.-Stat. Marion Ocak, MD research, Munich, Germany, for performing the statistical analysis of the data.

\section{Compliance statement}

All of the studies reported herein were performed in compliance with current, applicable, local laws and regulations.

\section{Disclosure statement}

D. Barutzki is the director of the Veterinary Laboratory Freiburg. R. Schaper is employee of Bayer Animal Health GmbH. Bayer Animal Health $\mathrm{GmbH}$ provided financial support for performance of data analysis. 


\section{References}

Barutzki D, Schaper R (2003) Endoparasites in dogs and cats in Germany 1999-2002. Parasitol Res 90:148-150.

Barutzki D, Schaper R (2009) Natural infections of Angiostrongylus vasorum and Crenosoma vulpis in dogs in Germany (2007-2009). Parasitol Res 105 (Suppl 1):39-48.

Batchelor DJ, Tzannes S, Graham PA, Wastling JM, Pinchbeck GL, German AJ (2008) Detection of endoparasites with zoonotic potential in dogs with gastrointestinal disease in the UK. Transbound Emerg Dis 55:99-104.

Beelitz P, Leonhard S, Pfister, K (2006) Giardia infections in Germany: evaluation of treatment regimes carried out in different types of pet keeping and prevalence. Prakt Tierarzt 87:597-603.

Buehl IE, Prosl H, Mundt H-C, Tichy AG, Joachim A (2006) Canine isosporosis - epidemiology of field and experimental infections. J Vet Med B 53:482-487.

Claerebout E, Casaert S, Dalemans A, De Wilde N, Levecke B, Vercruysse J, Geurden T (2009) Giardia and other intestinal parasites in different dog populations in Northern Belgium. Vet Parasitol 161:41-46.

Coati N, Hellmann K, Mencke N, Epe C (2003) Recent investigation on the prevalence of gastrointestinal nematodes in cats from France and Germany. Parasitol Res 90 (Suppl 3):146-147.

Daugschies A, Mundt H-C, Letkova V (2000) Toltrazuril treatment of cystoisosporosis in dogs under experimental and field conditions. Parasitol Res 86:797-799.

Dubná S, Langrová I, Nápravník J, Jankovská I, Vadlejch J, Pekár S, Fechtner J (2007) The prevalence of intestinal parasites in dogs from Prague, rural areas, and shelters of the Czech Republic. Vet Parasitol 145:120-128.

Epe C, Coati N, Schnieder T (2004) Results of parasitological examinations of faecal samples from horses, ruminants, pigs, dogs, cats, hedgehogs and rabbits between 1998 and 2002 . Dtsch Tierärztl Wochenschr 111:243-247.

Epe C, Rehkter G, Schnieder T, Lorentzen L, Kreienbrock L (2010) Giardia in symptomatic dogs and cats in Europe results of a European study. Vet Parasitol 173:32-38.

Fok E, Szatmári V, Busák K, Rozgonyi F (2001) Prevalence of intestinal parasites in dogs in some urban and rural areas of Hungary. Vet Quart 23:96-98.

Haralabidis ST, Papazachariadou MG, Koutinas AF, Rallis TS (1988) A survey on the prevalence of gastrointestinal parasites of dogs in the area of Thessaloniki, Greece. J Helminthol 62:45-49.
Hecking-Veltman J, Tenter AM, Daugschies A (2001) Studien zur Parasitenfauna bei streunenden Katzen im Raum Mönchengladbach. Prakt Tierarzt 82:563-569.

Heusinger A (2007) Giardieninfektionen. Kleintierpraxis $52: 245-248$.

Lindsay DS, Dubey JP, Blagburn BL (1997) Biology of Isospora spp. from humans, nonhuman primates, and domestic animals. Clin Microbiol Rev 10:19-34.

Marti H, Escher E (1990) SAF - an alternative fixation solution for parasitological specimens. Schweiz Med Wochenschr 120:1473-1476.

Martínez-Carrasco C, Berriatua E, Garijo M, Martínez J, Alonso FD, de Ybáñez RR (2007) Epidemiological study of non-systemic parasitism in dogs in southeast Mediterranean Spain assessed by coprological and post-mortem examination. Zoonoses Public Health 54:195-203.

Pullola T, Vierimaa J, Saari S, Virtala AM, Nikander S, Sukura A (2006) Canine intestinal helminths in Finland: prevalence, risk factors and endoparasite control practices. Vet Parasitol 140:321-326.

Rohen M (2009) Endoparasitenbefall bei Fund- und Abgabehunden und -katzen in Niedersachsen und Untersuchungen zur Anthelminthikaresistenz. Inaugural Dissertation 2009, Stiftung Tierärztlich Hochschule Hannover.

Sager H, Moret ChS, Grimm F, Deplazes P, Doherr MG, Gottstein B (2006) Coprological study on intestinal helminths in Swiss dogs: temporal aspects of anthelmintic treatment. Parasitol Res 98:333-338.

Scaramozzino P, Di Cave D, Berilli F, D’Orazi C, Spaziani A, Mazzanti S, Scholl F, De Liberato C (2009) A study of the prevalence and genotypes of Giardia duodenalis infecting kenneled dogs. Vet J 182:231-234.

Taubert A, Pantchev N, Vrhovec MG, Bauer C, Hermosilla C (2009) Lungworm infections (Angiostrongylus vasorum, Crenosoma vulpis, Aelurostrongylus abstrusus) in dogs and cats in Germany and Denmark in 2003-2007. Vet Parasitol 159:175-180.

Upjohn M, Cobb C, Monger J, Geurden T, Claerebout E, Fox M (2010) Prevalence, molecular typing and risk factor analysis for Giardia duodenalis infections in dogs in a central London rescue shelter. Vet Parasitol 172:341-346. 